\title{
Synthesis of 5-aryl-3-hydroxy-1-(2-hydroxypropyl)-4-(furyl-2-carbonyl)- 3-pyrrolin-2-ones and 5-aryl-3-hydroxy-1-(3-hydroxypropyl)- 4-(furyl-2-carbonyl)-3-pyrrolin-2-ones
}

\author{
(C) Daria D. Rubtsova, Alexandra A. Bobyleva, Daria D. Lezhnina, \\ Sofia V. Polikarpova, Polina A. Rozhkova, and Vladimir L. Gein*+ \\ Department of General and Organic Chemistry. Perm State Academy of Pharmacy. \\ Polevaya St., 2.Perm, 614090. Russia.Phone:+7 (342)236-90-50.E-mail: geinvl48@mail.ru
}

\begin{abstract}
*Supervising author; ${ }^{+}$Corresponding author
Keywords: 5-aryl-3-hydroxy-1-(2-hydroxypropyl)-4-(furyl-2-carbonyl)-3-pyrrolin-2-ones, 5-aryl-3-hydroxy-1-(3-hydroxypropyl)-4-(furyl-2-carbonyl)-3-pyrrolin-2-ones, synthesis.
\end{abstract}

Abstract
In this work, pyrrolidin-2-ones and their derivatives are considered as a promising class of non-aromatic heterocyclic compounds. Their structure is found in the nuclei of many natural products and biologically active molecules. In pharmacy the possibility of introducing various substituents into the nucleus of pyrrolidin-2-ones is a great importance for the synthesis of new medicinal molecules with improved biological activity. Nowadays the synthesis of new active compounds by introducing various substituents at the C1-, C4and C5-position of 3-hydroxy-3-pyrrolin-2-one has been little studied and it is of great interest to study the conditions of their synthesis, chemical properties and biological activity. In this research work the corresponding 5aryl-3-hydroxy-1-(2-hydroxypropyl)-4-(furyl-2-carbonyl)-3-pyrrolin-2-ones and 5-aryl-3-hydroxy-1-(3-hydroxypropyl)-4-(furyl-2-carbonyl)-3-pyrrolin-2-ones were synthesized by the reaction of methyl ester of furyl-2carbonylpyruvic acid with a mixture of aromatic aldehyde and 1-amino-2-hydroxypropane or 3-amino 1hydroxypropane when heated in dioxane. The results of the study of the structure of the new synthesized compounds are presented. The structure was proved using ${ }^{1} \mathrm{H}$ NMR spectroscopy and IR spectrometry. It was shown that the IR spectra of the compounds contain bands of the corresponding stretching vibrations of the alcoholic hydroxyl group, enol hydroxyl, amide and ketone groups. In the ${ }^{1} \mathrm{H}$ NMR spectra of the compounds, along with the signals of aromatic protons in the C5 substituent and related groups, characteristic peaks are observed, indicating the formation of the corresponding derivatives of 3-hydroxy-3-pyrrolin-2-ones. It was noted that in the case of the synthesis of 5-aryl-3-hydroxy-1-(2-hydroxypropyl)-4-(furyl-2-carbonyl)-3pyrrolin-2-ones, the signal of the methine proton at the $\mathrm{C} 5$ position of the heterocycle is cleaved in ${ }^{1} \mathrm{H}$ NMR spectra compounds as a result of the appearance of a second chiral center in the 2-hydroxypropyl radical. Elemental analysis was performed for the synthesized compounds.

\section{References}

[1] M.A. Mar'yasov, V.L. Gein. Tetragigropirrol-2,3-diony (Tetrahydropyrrole-2,3-diones). Perm: PGFA. 2013. 155p. (russian)

[2] X. Wei, S.P. Sumithran, A.G. Deaciuc, H.R. Burton, L.P. Bush, L.P. Dwoskin, P.A. Crooks. Identification and synthesis of novel alkaloids from the root system of Nicotiana European. Affinity for neuronal nicotinic acetylcholine receptors. Life Sci. 2005. Vol.78. No.5. P.495-505.

[3] D.-M. Ren, H.-F. Guo, W.-T. Yu, S.-Q. Wang, M. Ji, H.-X. Lou. Stereochemistry of flavonoidal alkaloids from Dracocephalum rupestre. Phytochem. 2008. Vol.69. No.6. P.1425-1433.

[4] K. Saurav, K. Kannabiran. Cytotoxicity and antioxidant activity of 5-(2, 4-dimethylbenzyl)pirrolidin-2one extracted from marine Streptomyces VITSVK5 spp. Saudi J. Biol. Sci. 2012. Vol.19. No.1. P.81-86.

[5] V.L. Gein, N.N. Kasimova, S.V. Chashchina, A.V. Starkova, A.N. Yankin. Synthesis and biological activity of 5-aryl-4-acyl-3-hydroxy-1-[2- (imidazol-3-yl) ethyl]-3-pyrrolin-2-ones. Russ. J. Gen. Chem. 2020. Vol.90. No.2. P.218-224. (russian)

[6] G. Ramachandran, N.S. Karthikeyan, P. Giridharan, K.I. Sathiyanarayanan. Efficient iodine catalyzed three components domino reaction for the synthesis of 1-((phenylthio)(phenyl)methyl)pyrrolidin-2-one derivatives possessing anticancer activities. Org. Biomol. Chem. 2012. Vol.10. No.28. P.5343-5346. 
SYNTHESIS OF 5-ARYL-3-HYDROXY-1-(2-HYDROXYPROPYL)-4-(FURYL-2-CARBONYL)-3-PYRROLIN-2-ONES... 26-30

[7] B. Malawska, K. Kulig, B. Filipek, J. Sapa, D. Maciąg, M. Zygmunt, L. Antkiewicz-Michaluk. Synthesis, antiarrhythmic, and antihypertensive effects of novel 1-substituted pyrrolidin-2-one and pyrrolidine derivatives with adrenolytic activity. Eur. J. Med. Chem. 2002. Vol.37. No.3. P.183-185.

[8] H. Ikuta, H. Shirota, S. Kobayashi, Y. Yamagishi, K. Yamada, I. Yamatsu, K. Katayama. Synthesis and anti-inflammatory activities of 3-(3,5-di-tert-butyl-4-hydroxybenzylidene)pyrrolidin-2-ones. J. Med. Chem. 1987. Vol.30. No.11. P.1995-1998.

[9] V.L. Gein, D.D. Rubtsova, A.A. Bobyleva, A.N. Yankin. Synthesis and antimicrobial activity of 5-aryl (heteryl)-3-hydroxy-1-hydroxyethyl-4-(furyl-2-carbonyl)-3-pyrrolin-2-ones. Russ. J. Gen. Chem. 2020. Vol.90. No.5. P.702-707. (russian)

[10] V.L. Gein, D.D. Rubtsova, A.A. Bobyleva, O.V. Ryabova, V.V. Novikova, N.N.Kasimova, A.N. Yankin. Synthesis and antimicrobial activity of 5-(het) aryl-3-hydroxy-1-hydroxyethyl-4-(thienyl-2carbonyl)-3-pyrrolin-2-ones. Russ. J. Gen. Chem. 2020. Vol.90. No.7. P.1033-1039. (russian) 